\title{
Glucose Transporter 1 and Hypoxia-Inducible Factor $1 a$ is Indicators of Head and Neck Squamous Cell Carcinoma Aggressiveness and Poor Prognosis: A Case Control Study
}

Jia Liu

Zhejiang University School of Medicine

Qiong Xu

Zhejiang University School of Medicine

Yun-Zhen Luo

Zhejiang University School of Medicine

Hong-Tian Yao

Zhejiang University School of Medicine

Shui-Hong Zhou (D1190051@zju.edu.cn)

Zhejiang University School of Medicine

\section{Research}

Keywords: head and neck, squamous cell carcinoma, glucose transporter 1, hypoxia-inducible factor-la, survival, prognosis

Posted Date: October 23rd, 2020

DOI: https://doi.org/10.21203/rs.3.rs-94543/v1

License: (c) (i) This work is licensed under a Creative Commons Attribution 4.0 International License.

Read Full License 


\section{Abstract}

Background: Head and neck squamous cell carcinoma (HNSCC) is a common and aggressive malignancy with a high morbidity and mortality profile. Increased levels of expression of the tumor hypoxia markers, hypoxia-inducible factor $1 \mathrm{a}$ (HIF-1a) and glucose transporter 1 (GLUT-1), are indicators of poor prognosis in carcinoma.

Materials and methods: This study involved detection of HIF-1 $a$ and GLUT-1 expression with a mean follow-up period of 10 years in 69 cases of HNSCC (23 cases of hypopharyngeal carcinoma and 46 of laryngeal carcinoma) and 30 controls ( 15 cases of vocal cord polyps and 15 of leukoplakia). The $\chi^{2}$ test, Fisher's exact probability method, Pearson's test, Kaplan-Meier method, Cox proportional hazards regression model of SPSS version 22.0 was used. In all analyses, $P<0.05$ was taken to indicate statistical significance.

Results: Compared with inflammatory and precancerous lesion tissues, the levels of GLUT-1 and HIF-1a expression were significantly increased in HNSCC $(P<0.001)$. There was a positive correlation between HIF-1a and GLUT-1 $(r=0.338, P=0.004)$. GLUT-1 expression was significantly associated with primary tumor site $(P=0.032)$, clinical stage $(P=0.036)$, lymph node metastasis $(P=0.032)$, and distant metastasis $(P=0.002)$. HIF-1a expression was significantly related to recurrence $(P=0.013)$, distant metastasis $(P=0.044)$, second primary cancer $(P=0.040)$, and overall survival (OS) $(P=0.029)$. The OS of the 69 patients with HNSCC was significantly associated with the primary tumor site $(P=0.024)$, clinical stage $(P=0.041)$, and lymph node metastasis $(P=0.039)$.

Conclusion: The increased levels of GLUT-1 and HIF-1 a expression may serve as molecular markers for diagnosis of HNSCC. High GLUT-1 and HIF-1a expression, especially HIF-1a expression, may be indicators of HNSCC aggressiveness and poor prognosis.

\section{Background}

Head and neck squamous cell carcinoma (HNSCC) is a common and aggressive malignancy with a high morbidity and mortality profile, and includes laryngeal and hypopharyngeal carcinoma. The majority of cases (90-95\%) are squamous cell carcinomas [1]. Laryngeal carcinoma is a particularly aggressive carcinoma type, and approximately $60 \%$ of patients present with locally advanced disease at diagnosis [2]. As the anatomical location of hypopharyngeal carcinoma is hidden and the early symptoms are not easy to detect, patients often arrive at the clinic in an advanced stage. Although hypopharyngeal carcinoma only accounts for $3-5 \%$ of carcinomas of the head and neck, it has poorer prognosis than other types [3]. It is important to explore the long-term survival and influencing factors of laryngeal and hypopharyngeal carcinomas, which can help in the evaluation of treatment strategies and patient education.

The exact cause of HNSCC remains unknown. However, some lifestyle behaviors, such as smoking, excessive consumption of alcohol, and poor diet, are known to increase the risk of carcinoma [4]. HNSCC 
carcinogenesis is a multi-factor, multi-stage process. Various genes and other biomarkers are altered at different stages of carcinoma progression [5]. Therefore, investigation of the mechanism of HNSCC occurrence and development, as well as prognostic factors of HNSCC invasion and metastasis, are important for the discovery of potential therapeutic targets.

Hypoxia is an inherent feature of solid tumors. When the tumor volume reaches $2 \mathrm{ml}$, the oxygen tension can be close to $0 \mathrm{mmHg}$ [6]. Hypoxia promotes the malignant transformation of tumors, induces tolerance of tumor cells to radiotherapy and chemotherapy, promotes tumor invasion and metastasis, and leads to poor prognosis. Following low oxygen treatment, laryngeal carcinoma cells exhibit strong abilities for invasion and formation of colonies and spheres [7]. Hypoxia promotes the expression of hypoxia-inducible factor (HIF), which plays an important role in the processes of infiltration, recurrence, and metastasis induced by hypoxia [8-9]. Previous studies also found that the expression of HIF-1a increased and was related to some biological behaviors of laryngeal carcinoma [10-13]. There have been few reports regarding the relationship between HIF-1a expression and the biological behavior of hypopharyngeal carcinoma.

Analysis using positron emission tomography (PET) confirmed that malignant tumors grow rapidly, require substantial amounts of energy, and have a high glucose metabolic rate. Increased absorption of fluoro-2-deoxyglucose, a glucose analog, was also found in hypopharyngeal carcinoma by PET and PET/computed tomography (CT) [14]. Glucose transporter (GLUT) plays an important role in this process. Although 14 GLUT proteins have been discovered to date, GLUT-1 plays a leading role in glucose uptake and transport in malignant tumor cells and is the subject of a great deal of research [15]. GLUT-1 is an intrinsic marker of hypoxia in malignant tumors and a downstream regulator of HIF-1 [16]. Both HIF-1a and GLUT-1 are markers of tumor hypoxia, and their co-expression is a marker of poor prognosis in carcinoma [17]. There have been few reports regarding the correlation between combined HIF-1 $a$ and GLUT-1 expression and biological behavior in HNSCC $[11-13,18]$. Notably, there have been no such reports regarding hypopharyngeal carcinoma.

In this study, the correlation setween clinicopathological characteristics and survival of patients with HNSCC were analyzed over a mean follow-up period of 10 years. The expression of HIF-1a and GLUT-1 in benign lesions, precancerous lesions, and laryngeal and hypopharyngeal carcinoma tissues was detected using immunohistochemistry. The relationships between HIF-1a and GLUT-1 expression, prognosis, and clinicopathological characteristics of the patients were analyzed.

\section{Materials And Methods}

\section{Patients}

The experimental group consisted of 69 patients with HNSCC confirmed by pathology (23 cases of hypopharyngeal carcinoma and 46 of laryngeal carcinoma) who were admitted to the Department of Otolaryngology of the First Affiliated Hospital of Zhejiang University Medical College (Hangzhou, China) and who underwent surgical resection between June 1, 2006, and January 1,2012. All tissue samples 
were collected prior to chemotherapy and/or radiotherapy. The control group consisted of 15 cases of pathologically confirmed vocal cord polyps (VCP) and 15 cases of pathologically confirmed vocal cord leukoplakia (VCL). This study was approved by the institutional review board of The First Affiliated Hospital, College of Medicine, Zhejiang University (Hangzhou, China). Informed consent was obtained from all patients.

\section{Demographic data and clinical data}

Data on sex, age, primary tumor site, tumor classification, clinical stage, lymph node metastasis, histological grade, recurrence, metastasis, and second primary carcinoma were collected for each HNSCC patient. Patients were also evaluated with regard to age $<60$ years and $\geq 60$ years. Tumor classification stage was conducted according to the Tumor-Node-Metastasis grading and clinical staging criteria of the International Union Against Carcinoma established in 2002 (Tis/T1/T2, T3/T4), clinical stage (early: $0 / I / I I$, late: III/IV), and histological grade according to the pathological results (well-differentiated, moderately differentiated, poorly differentiated) (Table 1 ).

\section{Detection of HIF-1a and GLUT-1 protein expression by immunohistochemistry}

Rabbit polyclonal antibody to human GLUT-1 (I:50 rabbit polyclonal; Santa Cruz Biotechnology, Santa Cruz, CA) and rabbit polyclonal antibody to human HIF-1a (1:100; Santa Cruz Biotechnology) were used. The results of immunohistochemistry were analyzed using ImagePro-Plus software (Media Cybernetics, Inc., Rockville, MD). Phosphate-buffered saline (PBS) was used in place of primary antibody as a negative control, with all other reaction conditions consistent with the experimental groups. The specimens were observed under a light microscope. GLUT-1 and HIF-1 a expression were detected in the cell nucleus or cytoplasm. Evaluation of immunohistochemistry was carried out according to the procedure reported previously [19]. Briefly, the expression levels of GLUT-1 and HIF-1 were assessed semiquantitatively using the product of these scores (staining intensity $\times \%$ positive cells): $0-5$ points $=$ negative $(-)$ and $6-12$ points $=$ positive $(+)$.

\section{Follow-up}

Follow-up was performed as described in our previous report. Briefly, the methods of follow-up included physical examination, laryngoscopy, and CT/MRI. Follow-up examination was performed every month during the first year after treatment, every 3 months in the second year, every 6 months in the third to fifth years, and every year after the fifth year. The last follow-up was July 1, 2020. Survival time was calculated from the date of patient discharge or end of radiation therapy to the patient's death or the date of the last follow-up or loss to follow-up.

\section{Statistical analysis}

The correlations between clinicopathological factors and HIF-1 $a$ and GLUT-1 were tested with the $\chi^{2}$ test and Fisher's exact probability method using SPSS version 22.0 for Windows (IBM Corp., Armonk, NY). 
Pearson's test was used for correlation analysis. Survival curves were calculated using the Kaplan-Meier method and compared with the results of the log-rank test. The Cox proportional hazards regression model was used for multivariate analysis. In all analyses, $P<0.05$ was taken to indicate statistical significance.

\section{Results}

\section{Patient characteristics}

A total of 69 paraffin-embedded HNSCC tissue specimens were collected, including 23 cases of hypopharyngeal squamous cell carcinoma and 46 cases of laryngeal carcinoma. The time interval from symptom detection to diagnosis ranged from 1 month to 10 years. Symptoms included hoarseness, sensation of a pharyngeal foreign body, pharyngeal pain, swallowing discomfort, swallowing difficulty, recurrent sputum with blood, dysphagia, swallowing obstruction, etc. The study population consisted of 65 men (94.2\%) and four women (5.8\%) ranging in age from 32 to 81 years (mean age: 60.6 years). There were 51 cases $(73.9 \%)$ of T1/T2 and 18 cases $(26.1 \%)$ of T3+T4+Tx. There were 37 cases (53.6\%) in the early clinical stage (I+II) and $32(46.4 \%)$ in the late stage (III/IV). Twenty-three cases (33.3\%) had lymph node metastasis. The study population included 33 (47.9\%), 21 (30.4\%), and 15 (21.7\%) cases with well, moderately, and poorly differentiated lesions, respectively. Twenty-six cases (37.7\%) had recurrence and 14 cases $(20.3 \%)$ had metastasis (Table 1 ). The controls consisted of 15 cases of pathologically confirmed VCP and 15 cases of pathologically confirmed VCL.

\section{Results of follow-up of patients with HNSCC}

The follow-up time ranged from four to 162 months (mean: 72 months). Of the 69 patients included in the study, 41 died and nine were lost to follow-up. Nine cases (13.0\%) developed a second primary carcinoma. There were five cases in patients with laryngeal carcinoma, consisting of one cases of kidney carcinoma, one of esophageal carcinoma, one of palatine arches carcinoma, and two of lung carcinoma. There were four cases in patients with hypopharyngeal carcinoma, including one oropharyngeal carcinoma and three of esophageal carcinoma.

The 3-, 5-, and 10-year overall survival (OS) rates of HNSCC were $68.0 \%, 46.0 \%$, and $29.0 \%$, respectively. In laryngeal carcinoma, the 3-, 5-, and 10-year os rates were $81.5 \%, 61.8 \%$, and $43.6 \%$, respectively. In hypopharyngeal carcinoma, the 3-, 5-, and 10-year OS rates were $66.7 \%, 30.8 \%$, and $15.4 \%$, respectively. The mean and median survival times of hypopharyngeal carcinoma were significantly shorter than those of laryngeal carcinoma $(93.4 \pm 7.6$ and $66.1 \pm 11.4$ vs. $104.0 \pm 25.4$ and $47.0 \pm 9.4$, respectively, $P=$ 0.030).

\section{Relationships between overall survival (OS) and clinicopathological parameters}

First, we performed univariate analysis. The results indicated that the OS of the 69 patients with HNSCC was significantly related to the primary tumor site $(P=0.024)$, clinical stage $(P=0.041)$, and lymph node 
metastasis $(P=0.039)$ (Figures 1$)$ (Table 1). OS of HNSCC was not significantly associated with age $(P=$ $0.880)$, T stage $(P=0.267)$, histological grade $(P=0.352)$, recurrence $(P=0.115)$, metastasis $(P=0.710)$, or second primary cancer $(P=0.561)$.

In stratified analysis of patients with laryngeal carcinoma, OS was not associated with age $(P=0.734), \mathrm{T}$ stage $(P=0.792)$, lymph node metastasis $(P=0.580)$, histological differentiation $(P=0.270)$, recurrence $(P=0.068)$, distant metastasis $(P=0.985)$, clinical stage $(P=0.142)$, or second primary cancer $(P=$ 0.918). In patients with hypopharyngeal carcinoma, OS was significantly related to histological grade ( $P$ $=0.002)$ and distant metastasis $(P=0.022)$ (Figure 2$)$. However, age $(P=0.743)$, T stage $(P=0.916)$, lymph node metastasis $(P=0.596)$, recurrence $(P=0.515)$, clinical stage $(P=0.678)$, and second primary cancer $(P=0.542)$ showed no correlation with OS in hypopharyngeal carcinoma.

Next, we performed multi-factor Cox proportional hazards regression analysis. OS was shown to be affected by various factors $\left(\chi^{2}=22.365, P=0.022\right)$. However, none of the factors examined showed a significant association with OS of HNSCCs. In stratified analysis of patients with laryngeal carcinoma, none of the factors showed significant associations with OS of laryngeal carcinoma. However, second primary cancer $(P=0.040)$ was significantly associated with OS of hypopharyngeal carcinoma (Table 2$)$.

\section{Expression of GLUT-1 and HIF-1a and their prognostic significance}

The positive rate of GLUT-1 expression in patients with HNSCC was $65.2 \%(45 / 69)$, which was significantly higher than those with VCP $[0.0 \%(0 / 15), P<0.001]$ or VCL $[20.0 \%(3 / 15), P=0.001]$ (Figures 3). There was no significant difference in GLUT-1 expression between VCP and VCL $(P=0.224)$ (Table 3). The OS of HNSCC was not significantly associated with GLUT-1 expression $(P=0.115)$. In stratified analysis, the rates of positivity for expression of GLUT-1 were $56.5 \%(26 / 46)$ in laryngeal carcinoma and $82.6 \%(19 / 23)$ in hypopharyngeal carcinoma. The level of GLUT-1 expression in laryngeal carcinoma was significantly lower than that in hypopharyngeal carcinoma $(P=0.032)$ (Table 4$)$. The OS rates of laryngeal carcinoma and hypopharyngeal carcinoma were not correlated with GLUT-1 expression ( $P=$ 0.386 and $P=0.375$, respectively). However, multi-factor Cox proportional hazards regression analysis showed that GLUT-1 $(P=0.004)$ was significantly associated with OS in hypopharyngeal carcinoma (Table 2).

The positive rate of HIF-1a expression in patients with HNSCC was $71.0 \%(49 / 69)$, which was significantly higher than those with VCP $[0.0 \%(0 / 15), P<0.001]$ and VCL $[13.3 \%(2 / 15), P<0.001]$. There was no significant difference in HIF-1a expression between VCP and VCL $(P=0.483)$. The OS of HNSCC was significantly associated with HIF-1a expression $(P=0.029)$ (Figures 1$)$. In stratified analysis, the positive rates of HIF-1a expression were $65.2 \%(30 / 46)$ in laryngeal carcinoma and $82.6 \%(19 / 23)$ in hypopharyngeal carcinoma. The rate of HIF-1a expression in laryngeal carcinoma was lower than that in hypopharyngeal carcinoma, but the difference was not significant $(P=0.133)$. The OS of laryngeal carcinoma and hypopharyngeal carcinoma were not correlated with HIF-1a expression $(P=0.071$ and $P$ 
$=0.658$, respectively). In addition, multi-factor Cox proportional hazards regression analysis showed the same results.

\section{Correlation between GLUT-1 and HIF-1a expression and clinicopathological factors of HNSCC}

In the 69 cases of HNSCC included in this study, GLUT-1 expression was significantly associated with clinical stage $(P=0.036)$, lymph node metastasis $(P=0.032)$, and distant metastasis $(P=0.002)$. However, age $(P=0.441)$, sex $(P=0.510), \mathrm{T}(P=0.468)$, histological differentiation $(P=0.314)$, recurrence $(P=0.112)$, and second primary cancer $(P=0.396)$ showed no association with GLUT-1. In addition, HIF1a expression was significantly associated with recurrence $(P=0.013)$, distant metastasis $(P=0.044)$, and second primary cancer $(P=0.040)$, but not with age $(P=0.446)$, sex $(P=0.856), \mathrm{T}(P=0.180)$, clinical stage $(P=0.081)$, lymph node metastasis $(P=0.133)$, or histological differentiation $(P=0.667)$ (Table 4).

In stratified analysis of the 46 laryngeal carcinoma patients, GLUT-1 expression was significantly associated with recurrence $(P=0.049)$ and distant metastasis $(P=0.001)$, but not with age $(P=0.796)$, sex $(P=0.714), \mathrm{T}(P=0.388)$, clinical stage $(P=0.065)$, lymph node metastasis $(P=0.133)$, histological differentiation $(P=0.304)$, or second primary cancer $(P=0.262)$. On the other hand, in laryngeal carcinoma, HIF-1 a expression was correlated with clinical stage $(P=0.020)$, lymph node metastasis $(P=$ $0.025)$, recurrence $(P=0.023)$, and distant metastasis $(P=0.005)$, but not with age $(P=0.404)$, sex $(P=$ $0.957), \mathrm{T}(P=0.216)$, histological differentiation $(P=0.299)$, or second primary cancer $(P=0.084)$ (Table 5). In stratified analysis of the 23 hypopharyngeal carcinoma patients, neither GLUT-1 nor HIF-1a expression were correlated with any of the clinicopathological factors examined (all $P>0.05$ ).

\section{Relationship between GLUT-1 and HIF-1a expression}

Among the 69 patients with HNSCC included in the study, positivity for both GLUT-1 and HIF-1a was detected in 37 cases. Pearson's correlation analysis showed a correlation between the expression of the two proteins $(r=0.338, P=0.004)$.

\section{Discussion}

Laryngeal carcinoma is a particularly aggressive type of carcinoma, with a 5-year OS rate of approximately 50\% [20]. The hypopharynx is located between the oropharynx and the esophagus, and hypopharyngeal carcinoma has a reported 5-year OS rate of approximately $30-35 \%$ [21]. Our results were similar to these previous studies, with $3-, 5$-, and 10 -year OS of $81.5 \%, 61.8 \%$, and $43.6 \%$, respectively, for laryngeal carcinoma and $66.7 \%, 30.8 \%$, and $15.4 \%$, respectively, for hypopharyngeal carcinoma. The survival time of hypopharyngeal carcinoma was significantly shorter than that of laryngeal carcinoma.

In this study, the OS of HNSCC was related to the primary tumor site, clinical stage, and lymph node metastasis. In patients with hypopharyngeal carcinoma, OS was significantly related to histological grade and distant metastasis. These observations were consistent with previous reports. Milan et al. analyzed 
387 patients with laryngeal carcinoma and found that 5-year survival rate was dependent on the localization of the primary tumor and TNM stage [22]. Xu et al. followed up 264 cases of hypopharyngeal carcinoma and reported that tumor classification $(P=0.039)$ and lymph node metastasis $(P=0.009)$ were correlated with survival [23]. However, in our previous study with 1-44 months (median:

13.7 months) of follow-up, the clinical stage $(P=0.249)$, lymph node metastasis $(P=0.924)$, and tumor differentiation $(P=0.875)$ showed no correlation with survival in patients with laryngeal or hypopharyngeal carcinoma [19]. These discrepancies may have been due to differences in follow-up time, clinical stage, or sample size. On the other hand, multi-factor Cox proportional hazards regression analysis in the present study showed that second primary cancer was significantly associated with OS of hypopharyngeal carcinoma. Xu et al. reported that second primary cancer accounted for $12.5 \%$ of deaths among patients with hypopharyngeal cancer [23]. This suggested that second primary cancer was correlated with the survival rate of hypopharyngeal cancer. Further studies in larger populations are necessary to clarify these points.

As HNSCC has a very low survival rate, a better understanding of the molecular biology of this disease is urgently required to support biomarker development and personalized care for patients [24]. There is a need for an indicator that can be used to assess rates of HNSCC survival, carcinoma metastasis, recurrence, and second primary carcinomas occurrence. In this study, HIF-1a and GLUT-1 expression in HNSCC were significantly increased in comparison with VCP and VCL $(P<0.01)$. This was consistent with our previous research [25-26] and with other studies $[11-13,27]$. In this respect, the expression levels of HIF-1a and GLUT-1 were different in malignant, benign, and precancerous lesions suggesting that they may serve as potential molecular markers for diagnosis of HNSCC.

In the present study, we found that the OS of laryngeal carcinoma and hypopharyngeal carcinoma were not correlated with GLUT-1 expression. However, multi-factor Cox proportional hazards regression analysis showed that GLUT-1 was significantly associated with OS of hypopharyngeal carcinoma. In addition, the OS of HNSCC was significantly associated with HIF-1a expression. These observations were consistent with the conclusions of other researchers. In our previous study, the positive expression of HIF1a was correlated with OS in patients with laryngeal carcinoma, while expression of GLUT-1 showed no correlation with OS [28]. Mao et al. reported that expression of GLUT-1 was not correlated with survival rate of laryngeal carcinoma [29]. In colorectal cancer, Yang et al. reported that GLUT-1 was not associated with OS or disease-free survival rate [30]. Shen et al. and Bao et al. reported that GLUT-1 expression was negatively correlated with survival [31-32]. Liang et al. reported that HIF-1a overexpression was closely related to tumor prognosis [33]. In patients with papillary thyroid carcinoma [34], pancreatic adenocarcinoma [35], pancreatic neuroendocrine tumors [36], epithelial ovarian cancer [37], and osteosarcoma [38], GLUT-1 and HIF-1a expression were reported to be correlated with total survival or disease-free survival rate. However, the relations between HIF-1 $\mathrm{a}$ and GLUT-1 expression and survival rate of patients remain controversial. Cabanillas et al. suggested that HIF-1a was not associated with the prognosis of supraglottic laryngeal squamous cell carcinoma [39]. In cervical cancer, Iwasaki et al. reported that HIF-1a and GLUT-1 expression were not correlated with disease-free survival [40]. These discrepancies may have been due to differences in tumor type, clinical stage, and methods used for 
detection and evaluation of GLUT-1 and HIF-1 a expression between studies. Our observations suggested that OS was correlated with GLUT-1 and HIF-1a expression (especially HIF-1a expression) in patients with laryngeal and hypopharyngeal carcinoma, but further studies are clearly warranted.

Many previous studies showed that GLUT-1 is expressed at high levels in laryngeal carcinoma and is involved in the development of radioresistance [31-32, 41]. Its expression was positively correlated with lymphatic metastasis. Inhibition of GLUT-1 using GLUT-1 antisense oligonucleotide and GLUT-1 small interfering RNA may enhance the radiosensitivity of laryngeal carcinoma cells [21-32, 41-42]. The results of this study showed that GLUT-1 was significantly correlated with the primary tumor site, clinical stage, lymph node metastasis, and metastasis. In a stratified analysis of the 46 laryngeal carcinoma patients, GLUT-1 expression was significantly associated with recurrence and distant metastasis. In addition, the results showed that the expression of GLUT-1 in hypopharyngeal carcinoma was higher than that recorded in laryngeal carcinoma. There have been no previous studies comparing the expression of GLUT-1 in laryngeal and hypopharyngeal carcinoma.

HIF-1a is overexpressed in a variety of solid tumors, such as breast, prostate, ovary, and primary glioma $[33,43-44]$, suggesting that it is closely related to tumor progression and metastasis. HIF-1a is also highly expressed in some precancerous lesions [45], but low or absent in a variety of benign tumors [46]. Chen et al. reported that the expression level of HIF-1a differs with the degree of tumor differentiation and the ability to infiltrate and metastasize [47]. Therefore, the study of HIF-1a is of great significance for tumor growth, invasion, and metastasis, as well as treatment. The results of this study showed that the increased expression of HIF-1 a was significantly correlated with recurrence and metastasis of HNSCC. In laryngeal carcinoma, HIF-1 a expression was correlated with clinical stage, lymph node metastasis, recurrence, and distant metastasis, consistent with previous observations [33]. Yu et al. reported that HIF1a was associated with lymph node metastasis in laryngeal carcinoma [48]. Cabanillas et al. reported a significant positive correlation between HIF-1a and tumor classification [39], and their results were consistent with those of the present study. In summary, we found that GLUT-1 and HIF-1a expression were correlated with clinicopathological factors and prognosis of patients with laryngeal and hypopharyngeal carcinoma. GLUT-1 and HIF-1 a may be indicators of tumor aggressiveness and poor prognosis.

HIF-1a and GLUT-1 are used as markers of intrinsic hypoxia in tumor tissues [26]. There is a significant positive correlation between HIF-1a and GLUT-1 [11 - 13]. Hayashi et al. proposed the following mechanism of hypoxia-induced GLUT-1 expression: in the case of hypoxia, the expression of HIF-1a increases sharply, and the enhancer sequence at the $5^{\prime}$-terminus of GLUT-1 is activated, thereby increasing the expression of GLUT-1, and subsequently increased glucose transport and glucose degradation contribute to the tolerance of tissue cells to ischemia and hypoxia [27]. The results of the present study showed that HIF-1a expression was positively correlated with GLUT-1 expression in HNSCC. However, Schrijvers et al. reported that the results of immunohistochemical analysis in glottic laryngeal carcinoma did not show a significant correlation between HIF-1a and GLUT-1 expression, which was inconsistent with our observations [49]. Further studies regarding this issue are therefore required. 


\section{Conclusion}

Based on a mean follow-up period of 10 years, the survival rate of hypopharyngeal carcinoma was significantly lower than that of laryngeal carcinoma. The OS of HNSCC was related to the primary tumor site, clinical stage, and lymph node metastasis. In patients with hypopharyngeal carcinoma, OS was significantly related to histological grade and distant metastasis. Second primary cancer was suggested to be correlated with the survival rate of hypopharyngeal cancer. The increased expression of GLUT-1 and HIF-1a may serve as potential molecular markers for HNSCC diagnosis. The OS of patients with laryngeal and hypopharyngeal carcinoma were correlated with GLUT-1 and HIF-1 a expression (especially HIF-1a expression). There was a significant positive correlation between HIF-1a and GLUT-1, and both GLUT-1 and HIF-1a expression were correlated with clinicopathological factors and prognosis of patients with laryngeal and hypopharyngeal carcinoma. GLUT-1 and HIF-1 a may be indicators of tumor aggressiveness and poor prognosis. Further studies with larger sample sizes and additional experiments are required to verify these results.

\section{List Of Abbreviations}

\begin{tabular}{ll} 
HIF-1a & Hypoxia inducible factor $1 \mathrm{a}$ \\
\hline HNSCC & head and neck squamous cell carcinoma \\
\hline VCP & vocal cord polyps \\
\hline CSCs & carcinoma stem cells
\end{tabular}

\begin{tabular}{ll} 
GLUT-1 & glucose transporter 1 \\
\hline PET & positron emission tomography \\
\hline VCL & vocal cord leukoplakia \\
\hline
\end{tabular}

\section{Declarations}

\section{Ethics approval and consent to participate}

This study was approved by the institutional review board of The First Affiliated Hospital, College of Medicine, Zhejiang University (Hangzhou, China). Informed consent was obtained from all patients.

\section{Consent for publication}

Not applicable

\section{Availability of data and materials}


All data generated or analysed during this study are included in this published article [and its supplementary information files].

\section{Competing interests}

The authors declare that they have no competing interests.

\section{Funding}

This research was supported byNational Natural Science Foundation of China (No. 81372903).

\section{Authors' contributions}

LJ collected patient information and was a major contributor in writing the manuscript.

XQ record follow-up information.

L Y-Z performed the Immunohistochemical experiment.

Y H-T performed the pathological examination.

Z S-H was a major contributor in designing this experiments.

\section{Acknowledgements}

Not applicable

\section{References}

1. Pracy P, Loughran S, Good J, et al. Hypopharyngeal cancer: United Kingdom National Multidisciplinary Guidelines. J Laryngol Otol. 2016;130(suppl S2):104-10.

2. Salvador-Coloma C, Cohen E. Multidisciplinary care of laryngeal cancer. J Oncol Pract. 2016 Aug;12(8):717-24.

3. Takes RP, Strojan P, Silver CE, et al. International Head and Neck Scientific Group. Current trends in initial management of hypopharyngeal cancer: the declining use of open surgery. Head Neck. 2012 Feb;34(2):270-81.

4. Bravi F, Lee YC, Hashibe M, et al. Lessons Learned From the INHANCE Consortium: An Overview of Recent Results on Head and Neck Cancer. Oral Dis. 2020;22:387-403.

5. Stransky N, Egloff AM, Tward AD. The mutational landscape of head and neck squamous cell carcinoma. Science. 2011;26:1157-60.

6. Guppy M. The hypoxic core: a possible answer to the cancer paradox. Biochem Biophys Res Commun. 2002;299:676-80. 
7. Ferrer A, Roser CT, El-Far MH, et al. Hypoxia-mediated changes in bone marrow microenvironment in breast cancer dormancy. Cancer Lett. 2020 Sep 28;488:9-17.

8. Hajizadeh F, Ardebili SM, Moornani MB, et al. Silencing of HIF-1a/CD73 axis by siRNA-loaded TATchitosan-spion nanoparticles robustly blocks cancer cell progression.. Eur J Pharmacol. 2020 Jun 20:173235.

9. Nusblat LM, Tanna S, Roth CM. Gene silencing of HIF-2a disrupts glioblastoma stem cell phenotype. Cancer Drug Resist. 2020;3(2):199-208.

10. Wu XH, Lu YF, Hu XD, et al. Expression of hypoxia inducible factor-1a and its significance in laryngeal carcinoma. J Int Med Res. 2010;38(6):2040-6.

11. Wei L, ChenYY, Qi Y, Zhou SH, et al. Expression of glucose transporter-1, hypoxia inducible factor-1a and beclin-1 in head and neck cancer and their implication. Int J Clin Exp Pathol. 2018;11(7):370817.

12. Shen LF, Zhao X, Zhou SH, et al. In vivo evaluation of the effects of simultaneous inhibition of GLUT1 and HIF-1a by antisense oligodeoxynucleotides on the radiosensitivity of laryngeal carcinoma using micro 18F-FDG PET/CT. Oncotarget. 2017;8(21):34709-26.

13. Jiang T, Zhou ML, Fan J. Inhibition of GLUT-1 expression and the PI3K/Akt pathway to enhance the chemosensitivity of laryngeal carcinoma cells in vitro. OncoTargets Therapy. 2018;11:7865-72.

14. Ng SH, Chan SC, Yen TC, et al. PET/CT and 3-T whole-body MRI in the detection of malignancy in treated oropharyngeal and hypopharyngeal carcinoma. Eur J Nucl Med Mol Imaging. 2011;38(6):996-1008.

15. Zhong JT, Yu Q, Zhou SH, et al. GLUT-1 siRNA Enhances Radiosensitization Of Laryngeal Cancer Stem Cells Via Enhanced DNA Damage, Cell Cycle Redistribution, And Promotion Of Apoptosis In Vitro And In Vivo. Onco Targets Ther. 2019 Nov;5(12):9129-42.

16. Cheng J, Kang X, Zhang S, et al. SUMO-specific protease 1 is essential for stabilization of HIF1alpha during hypoxia. Cell. 2007;131(3):584-95.

17. Lu ZJ, Yu Q, Zhou SH, et al. Construction of a GLUT-1 and HIF-1a gene knockout cell model in HEp-2 cells using the CRISPR/Cas9 technique. Cancer Manag Res 2019 Mar; 8(11):2087-2096.

18. Amornphimoltham $P$, Patel $V$, Leelahavanichkul $K$, et al. A retroinhibition approach reveals a tumor cell-autonomous response to rapamycin in head and neck cancer. Cancer Res. 2008;68(4):1144-53.

19. Shen LF, Zhou SH, Yu Q. Relationships between expression of glucose transporter protein-1 and hypoxia inducible factor-1a, prognosis and 18F-FDG uptake in laryngeal and hypopharyngeal carcinomas. Transl Cancer Res. 2020;9(4):2824-37.

20. Tanadech D. Epidemiology, risk factors, and overall survival rate of laryngeal cancer in Songklanagarind Hospital. J Med Assoc Thai. 2011 Mar;94(3):355-60.

21. Jonathan CG, Richard LB, Brett AM. Hypopharyngeal cancer: A state of the art review. Oral Oncol. 2018 Nov;86:244-50. 
22. Stankovic M, Milisavljevic D, Zivic M, et al. Influential factors, complications and survival rate of primary and salvage total laryngectomy for advanced laryngeal cancer. Coll Antropol. 2012 Nov;36(Suppl 2):7-12.

23. Xu W, Lyu ZH, Sa N, et al. Treatment and prognosis of 264 patients with hypopharyngeal carcinoma. Zhonghua Er Bi Yan Hou Tou Jing Wai Ke Za Zhi. 2018 May;53(5):346-51.

24. Jou A, Hess J. Epidemiology and Molecular Biology of Head and Neck Cancer. Oncol Res Treat. 2017;40:328-32.

25. Wu XH, Lu YF, Hu XD, et al. Expression of hypoxia inducible factor-1a and its significance in laryngeal carcinoma. J Int Med Res. 2010;38(6):2040-6.

26. Zhou SH, Fan J, Chen XM, et al. Inhibition of cell proliferation and glucose uptake in human laryngeal carcinoma cells by antisense oligonucleotides against glucose transporter-1. Head Neck. 2009;31:1624-33.

27. Hayash M, Sakata M, Takeda T. et a1. Induction of glucose transporter 1 expression through hypoxiainducible factor 1 alpha under hypoxia conditions in trophoblast-derived. cellsEndocrinol. 2004;183(10):145-54.

28. Zhao K, Yang SY, Zhou SH, et al. Fluorodeoxyglucose uptake in laryngeal carcinoma is associated with the expression of glucose transporter- 1 and hypoxia-inducible-factor-1alpha and the phosphoinositide 3-kinase/protein kinase B pathway. Oncol Lett. 2014;7:984-90.

29. Mao ZP, Zhao LJ, Zhou SH, et al. Expression and significance of glucose transporter-1, Pglycoprotein, multidrug resistance-associated protein and glutathione S-transferase-pi in laryngeal carcinoma. Oncol Lett. 2015;9:806-10.

30. Yang J, Wen J, Tian T, et al. GLUT-1 overexpression as an unfavorable prognostic biomarker in patients with colorectal cancer. Oncotarget. 2017;8:11788-96.

31. Shen LF, Zhao X, Zhou SH. In vivo evaluation of the effects of simultaneous inhibition of GLUT-1 and HIF-1 alpha by antisense oligodeoxynucleotides on the radiosensitivity of laryngeal carcinoma using micro 18F-FDG PET/CT. Oncotarget. 2017;8:34709-26.

32. Bao YY, Zhou SH, Lu ZJ, et al. Inhibiting GLUT-1 expression and PI3K/Akt signaling using apigenin improves the radiosensitivity of laryngeal carcinoma in vivo. Oncol Rep. 2015;34:1805-14.

33. Liang DM, Ma YY, Liu J, et al. The hypoxic microenvironment upgrades stem-like properties of ovarian cancer cells. BMC Cancer. 2012;12:201.

34. Chai YJ, Yi JW, Oh SW, et al. Upregulation of SLC2 (GLUT) family genes is related to poor survival outcomes in papillary thyroid carcinoma: Analysis of data from The Cancer Genome Atlas. Surgery 2017;161:188 - 94.

35. Davis-Yadley AH, Abbott AM, Pimiento JM, et al. Increased Expression of the Glucose Transporter Type 1 Gene Is Associated With Worse Overall Survival in Resected Pancreatic Adenocarcinoma. Pancreas. 2016;45:974-9.

36. Fujino M, Aishima S, Shindo K, et al. Expression of glucose transporter-1 is correlated with hypoxiainducible factor 1 alpha and malignant potential in pancreatic neuroendocrine tumors. Oncol Lett. 
2016;12:3337-43.

37. Cho H, Lee YS, Kim J, et al. Overexpression of glucose transporter-1 (GLUT-1) predicts poor prognosis in epithelial ovarian cancer. Cancer Invest. 2013;31:607-15.

38. Kubo T, Shimose S, Fujimori J, et al. Does expression of glucose transporter protein-1 relate to prognosis and angiogenesis in osteosarcoma? Clin Orthop Relat Res. 2015;473:305-10.

39. Cabanillas R, Rodrigo JP, Secades P, et al. The relation between hypoxia-inducible factor (HIF)-1alpha expression with p53 expression and outcome in surgically treated supraglottic laryngeal cancer. $\mathrm{J}$ Surg Oncol. 2009;99:373-8.

40. Iwasaki K, Yabushita H, Ueno T, et al. Role of hypoxia-inducible factor-1alpha, carbonic anhydrase-IX, glucose transporter-1 and vascular endothelial growth factor associated with lymph node metastasis and recurrence in patients with locally advanced cervical cancer. Oncol Lett. 2015;10:1970-8.

41. Luo XM, Xu B, Zhou ML. Co-inhibition of GLUT-1 expression and the PI3K/Akt signaling pathway to enhance the radiosensitivity of laryngeal carcinoma xenografts in vivo. PLoS One. 2015;10:e0143306.

42. Yan SX, Luo XM, Zhou SH. Effect of antisense oligodeoxynucleotides glucose transporter-1 on enhancement of radiosensitivity of laryngeal carcinoma. Int J Med Sci. 2013;10:1375-86.

43. Conley SJ, Gheordunescu E, Kakarala P. Antiangiogenic agents increase breast cancer stem cells via the generation of tumor hypoxia. Proc Natl Acad Sci USA. 2012;109:2784-9.

44. Li PC, Zhou C, Xu LS, et al. Hypoxia enhances stemness of cancer stem cells in glioblastoma: an in vitro study. Int J Med Sci. 2013;10:399-407.

45. Simiantonaki N, Taxeidis M, Jayasinghe C, et al. Hypoxia-inducible factor 1 alpha expression increases during colorectal carcinogenesis and tumor progression. BMC Cancer. 2008;8:320.

46. Kaira K, Okumura T, Ohde Y, et al. Correlation between 18F-FDG uptake on PET and molecular biology in metastatic pulmonary tumors. J Nucl Med. 2011;52(5):705-11.

47. Chen J, Zhao S, Nakada K, et al. Dominant-negative hypoxia-inducible factor-1 alpha reduces tumorigenicity of pancreatic cancer cells through the suppression of glucose metabolism. Am J Pathol. 2003;162(4):1283-91.

48. Yu L, Liu Y, Cui Y. Expression of hypoxia inducible factor-1alpha and its relationship to apoptosis and proliferation in human laryngeal squamous cell carcinoma. J Huazhong Univ Sci Technolog Med Sci. 2004;24:636-8.

49. Schrijvers $M L$, vanderLaan $B F$, deBock $\mathrm{GH}$, et al. Overexpression of intrinsic hypoxia markers HIF1alpha and CA-IX predict for local recurrence in stage T1-T2 glottic laryngeal carcinoma treated with radiotherapy. Int J Radiat Oncol Biol Phys. 2008;72:161-9.

\section{Tables}


Table 1

Correlation of the survival of patients with HNSCC, clinicopathological characteristics and expression of GLUT-1 and HIF-1a.

\begin{tabular}{|c|c|c|c|c|}
\hline Characteristics & No. (\%) & Means of survival time & $\chi^{2}$ & P value \\
\hline \multicolumn{5}{|l|}{ Gender } \\
\hline Male & $65(94.2)$ & $92.1 \pm 7.5$ & 5.185 & 0.023 \\
\hline Female & $4(5.8)$ & $37.0 \pm 0.58$ & & \\
\hline \multicolumn{5}{|l|}{ Age } \\
\hline$<60$ & $33(47.8)$ & $87.32 \pm 10.41$ & 0.023 & 0.880 \\
\hline$\geq 60$ & $36(52.2)$ & $89.29 \pm 9.78$ & & \\
\hline \multicolumn{5}{|l|}{ Primary tumor site } \\
\hline Larynx & $46(66.7)$ & $93.39 \pm 7.57$ & 5.127 & $0.024^{\star}$ \\
\hline Hypopharynx & 23(33.3) & $66.09 \pm 11.39$ & & \\
\hline \multicolumn{5}{|l|}{ Tumour classification } \\
\hline $\mathrm{T}_{1+} \mathrm{T}_{2}$ & $51(73.9)$ & $93.41 \pm 8.31$ & 1.232 & 0.267 \\
\hline $\mathrm{T}_{3+} \mathrm{T}_{4}+\mathrm{T}_{\mathrm{x}}$ & $18(26.1)$ & $76.23 \pm 14.20$ & & \\
\hline \multicolumn{5}{|l|}{ Clinical stage } \\
\hline$I+\|$ & $37(53.6)$ & $103.20 \pm 9.13$ & 4.163 & $0.041^{*}$ \\
\hline III + IV & $32(46.4)$ & $71.28 \pm 10.56$ & & \\
\hline \multicolumn{5}{|l|}{ Lymph node metastasis } \\
\hline No & $46(66.7)$ & $96.48 \pm 8.17$ & 4.262 & $0.039 *$ \\
\hline Yes & $23(33.3)$ & $71.36 \pm 13.08$ & & \\
\hline \multicolumn{5}{|l|}{ Histological grade } \\
\hline Well differentiated & $33(47.9)$ & $101.05 \pm 9.75$ & 2.089 & 0.352 \\
\hline Moderately differentiated & $21(30.4)$ & $74.17 \pm 10.50$ & & \\
\hline Poorly differentiated & 15(21.7) & $73.38 \pm 17.56$ & & \\
\hline \multicolumn{5}{|l|}{ Recurrence } \\
\hline yes & $26(37.7)$ & $72.38 \pm 10.65$ & 2.481 & 0.115 \\
\hline \multicolumn{5}{|c|}{ GLUT-1, glucose transporter 1 ; HIF-1a, hypoxia inducible factor $1 \mathrm{a}$. } \\
\hline * denotes statistical differ & es $(P<C$ & & & \\
\hline
\end{tabular}




\begin{tabular}{|lllll|}
\hline Characteristics & No. (\%) & Means of survival time & $\chi^{2}$ & P value \\
\hline no & $43(62.3)$ & $95.99 \pm 9.01$ & & \\
\hline Metastasis & & & & \\
\hline yes & $14(20.3)$ & $79.47 \pm 15.59$ & 0.138 & 0.710 \\
\hline No & $55(79.7)$ & $90.83 \pm 7.98$ & 0.337 & 0.561 \\
Second primary cancer & $9(13.0)$ & $87.22 \pm 12.48$ & & \\
Yes & $60(87.0)$ & $90.00 \pm 8.27$ & & \\
\hline No & & & & \\
\hline HIF-1a & & & & \\
\hline Negative & $20(29.0)$ & $106.16 \pm 11.21$ & & \\
\hline Positive & $49(71.0)$ & $78.96 \pm 8.32$ & & \\
\hline GLUT-1 & & & & \\
\hline Negative & $24(34.8)$ & $102.80 \pm 10.25$ & & \\
\hline Positive & $45(65.2)$ & $79.95 \pm 9.31$ & & \\
\hline GLUT-1, glucose transporter $1 ;$ HIF-1a, hypoxia inducible factor $1 \mathrm{a}$. & & \\
\hline * denotes statistical differences $(\mathrm{P}<0.05)$. & & & \\
\hline
\end{tabular}


Table 2

Cox proportional hazards regression model results of survival of patients with hypopharyngeal carcinoma (Enter-method).

\begin{tabular}{|c|c|c|c|c|c|c|c|c|}
\hline & B & SE & Wald & df & Sig. & $\operatorname{Exp}(B)$ & \multicolumn{2}{|c|}{$\begin{array}{l}95.0 \% \mathrm{Cl} \text { for } \\
\operatorname{Exp}(\mathrm{B})\end{array}$} \\
\hline & Lower & Upper & Lower & Upper & Lower & Upper & Lower & Upper \\
\hline HIF1a & .851 & 1.361 & 0.391 & 1 & .532 & 2.342 & .163 & 33.716 \\
\hline GLUT-1 & 5.790 & 1.986 & 8.502 & 1 & $.004^{*}$ & 327.025 & 6.674 & 16025.0 \\
\hline $\begin{array}{l}\text { Tumour } \\
\text { classificatin }\end{array}$ & 2.031 & 1.380 & 2.165 & 1 & .141 & 7.618 & .510 & 113.879 \\
\hline Clinical stage & .597 & 1.531 & .152 & 1 & .697 & 1.816 & .090 & 36.499 \\
\hline $\begin{array}{l}\text { Lymphnode } \\
\text { metastasis }\end{array}$ & -.002 & 1.251 & .000 & 1 & .999 & .998 & .086 & 11.589 \\
\hline Histological grade & -.3 .019 & 1.788 & 2.651 & 1 & .091 & .049 & .001 & 1.624 \\
\hline Recurrence & -.080 & 1.301 & .004 & 1 & .951 & .923 & .072 & 11.819 \\
\hline Metastasis & -1.830 & 1.432 & 1.633 & 1 & .201 & 0.160 & .010 & 2.656 \\
\hline $\begin{array}{l}\text { Second primary } \\
\text { cancer }\end{array}$ & -3.334 & 1.624 & 4.214 & 1 & $.040^{\star}$ & .036 & .001 & 0.860 \\
\hline \multicolumn{9}{|c|}{ GLUT-1, glucose transporter 1 ; HIF-1a, hypoxia inducible factor $1 a_{\text {; }}$} \\
\hline * denotes statistic & erence & $<0.05)$ & & & & & & \\
\hline
\end{tabular}

Table 3

Expression of GLUT-1 and HIF-1a in VCP, VCL and HNSCC.

\begin{tabular}{|c|c|c|c|c|c|c|c|c|c|}
\hline \multirow[t]{2}{*}{ Disease } & \multirow[t]{2}{*}{ Total number } & \multicolumn{2}{|c|}{ GLUT-1 } & \multirow[t]{2}{*}{$\chi^{2}$} & \multirow[t]{2}{*}{$P$ value } & \multicolumn{2}{|c|}{ HIF-1a } & \multirow[t]{2}{*}{$\chi^{2}$} & \multirow[t]{2}{*}{ P value } \\
\hline & & + & - & & & + & - & & \\
\hline VCP & 15 & 0 & 15 & Fisher & $0.000^{\wedge}$ & 0 & 15 & Fisher & $0.000^{\Delta}$ \\
\hline VCL & 15 & 3 & 12 & 10.287 & $0.001^{\square}$ & 2 & 13 & 17.187 & $0.000^{\square}$ \\
\hline HNSCC & 69 & 45 & 24 & & & 49 & 20 & & \\
\hline
\end{tabular}

$\Delta$ represents a comparison between vocal cord polyps and HNSCC

$\square$ represents a comparison between vocal cord leukoplakia and HNSCC.

GLUT-1, glucose transporter 1; HIF-1a, hypoxia inducible factor $1 \mathrm{a}$; HNSCC, head and neck squamous cell carcinoma; VCP, vocal cord polyps; VCL, vocal cord leukoplakia 
Table 4

Correlation between GLUT-1 and HIF-1a expression and clinicopathological factors of HNSCC

\begin{tabular}{|c|c|c|c|c|c|c|c|c|c|}
\hline \multirow[t]{2}{*}{ Factors } & \multirow[t]{2}{*}{ Case } & \multicolumn{2}{|c|}{ GLUT-1 } & \multirow[t]{2}{*}{$x^{2}$} & \multirow[t]{2}{*}{$P$ value } & \multicolumn{2}{|c|}{ HIF-1a } & \multirow[t]{2}{*}{$x^{2}$} & \multirow[t]{2}{*}{$P$ value } \\
\hline & & + & - & & & + & - & & \\
\hline \multicolumn{10}{|l|}{ age } \\
\hline$\nabla 60$ & 33 & 20 & 13 & 0.593 & 0.441 & 22 & 11 & 0.581 & 0.446 \\
\hline$\geq 60$ & 36 & 25 & 11 & & & 27 & 9 & & \\
\hline \multicolumn{10}{|l|}{ sex } \\
\hline Male & 65 & 43 & 22 & 0.433 & 0.510 & 46 & 19 & 0.033 & 0.856 \\
\hline Female & 4 & 2 & 2 & & & 3 & 1 & & \\
\hline \multicolumn{10}{|l|}{ Primary tumor site } \\
\hline Larynx & 46 & 26 & 20 & 4.600 & $0.032^{\star}$ & 30 & 16 & 2.253 & 0.133 \\
\hline Hypopharynx & 23 & 19 & 4 & & & 19 & 4 & & \\
\hline \multicolumn{10}{|l|}{ Tumour classificatin } \\
\hline$T_{1+} T_{2}$ & 51 & 32 & 19 & 0.527 & 0.468 & 34 & 17 & 1.795 & 0.180 \\
\hline$T_{3+} T_{4 a}+T_{x}$ & 18 & 13 & 5 & & & 15 & 3 & & \\
\hline Clinical stage & 37 & 20 & 17 & 4.383 & $0.036^{\star}$ & 23 & 14 & 3.037 & 0.081 \\
\hline $1+11$ & 32 & 25 & 7 & & & 26 & 6 & & \\
\hline \multicolumn{10}{|l|}{ III + IV } \\
\hline \multicolumn{10}{|l|}{ Lymph node metastasis } \\
\hline No & 46 & 26 & 20 & 4.600 & $0.032^{\star}$ & 30 & 16 & 2.253 & 0.133 \\
\hline Yes & 23 & 19 & 4 & & & 19 & 4 & & \\
\hline \multicolumn{10}{|l|}{ Histological grade } \\
\hline Well differentiated & 33 & 19 & 14 & 2.314 & 0.314 & 23 & 10 & 0.809 & 0.667 \\
\hline Moderately differentiated & 21 & 14 & 7 & & & 14 & 7 & & \\
\hline Poorly differentiated & 15 & 12 & 3 & & & 12 & 3 & & \\
\hline
\end{tabular}

GLUT-1, glucose transporter 1; HIF-1a, hypoxia inducible factor $1 \mathrm{a} ; \mathrm{HNSCC}$, head and neck squamous cell carcinoma

* denotes statistical differences $(P<0.05)$. 


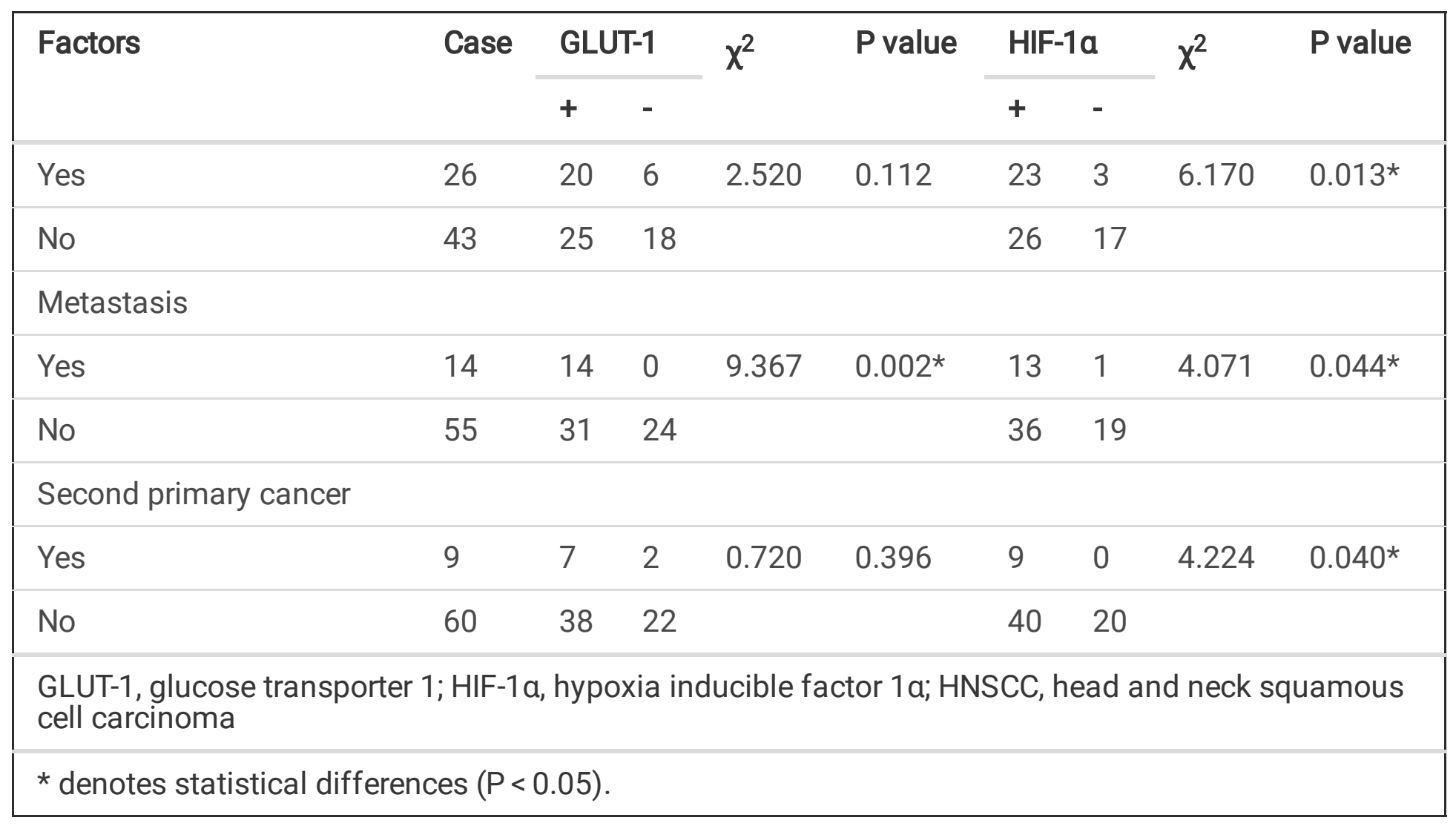


Table 5

Correlation between GLUT-1 and HIF-1a expression and clinicopathological factors of laryngeal carcinoma.

\begin{tabular}{|c|c|c|c|c|c|c|c|c|c|}
\hline \multirow[t]{2}{*}{ Factors } & \multirow[t]{2}{*}{ Case } & \multicolumn{2}{|c|}{ GLUT-1 } & \multirow[t]{2}{*}{$x^{2}$} & \multirow[t]{2}{*}{$P$ value } & \multicolumn{2}{|c|}{ HIF-1a } & \multirow[t]{2}{*}{$x^{2}$} & \multirow[t]{2}{*}{$P$ value } \\
\hline & & + & - & & & + & - & & \\
\hline \multicolumn{10}{|l|}{ age } \\
\hline$\nabla 60$ & 22 & 12 & 10 & 0.067 & 0.796 & 13 & 9 & 0.698 & 0.404 \\
\hline$\geq 60$ & 24 & 14 & 10 & & & 17 & 7 & & \\
\hline \multicolumn{10}{|l|}{ sex } \\
\hline Male & 43 & 24 & 19 & 0.134 & 0.714 & 28 & 15 & 0.003 & 0.957 \\
\hline Female & 3 & 2 & 1 & & & 2 & 1 & & \\
\hline \multicolumn{10}{|l|}{ Tumour classificatin } \\
\hline$T_{1+} T_{2}$ & 39 & 21 & 18 & 0.747 & 0.388 & 24 & 15 & 1.529 & 0.216 \\
\hline$T_{3+} T_{4 a}+T_{x}$ & 7 & 5 & 2 & & & 6 & 1 & & \\
\hline Clinical stage & 30 & 14 & 16 & 3.409 & 0.065 & 16 & 14 & 5.370 & $0.020 *$ \\
\hline$I+I I$ & 16 & 12 & 4 & & & 14 & 2 & & \\
\hline \multicolumn{10}{|l|}{ III + IV } \\
\hline \multicolumn{10}{|l|}{ Lymph node metastasis } \\
\hline No & 34 & 17 & 17 & 2.256 & 0.133 & 19 & 15 & 5.007 & $0.025^{\star}$ \\
\hline Yes & 12 & 9 & 3 & & & 11 & 1 & & \\
\hline \multicolumn{10}{|l|}{ Histological grade } \\
\hline Well differentiated & 21 & 11 & 10 & 2.382 & 0.304 & 12 & 9 & 2.417 & 0.299 \\
\hline Moderately differentiated & 13 & 6 & 7 & & & 8 & 5 & & \\
\hline Poorly differentiated & 12 & 9 & 3 & & & 10 & 2 & & \\
\hline \multicolumn{10}{|l|}{ Recurrence } \\
\hline Yes & 19 & 14 & 5 & 3.880 & $0.049^{*}$ & 16 & 3 & 5.148 & $0.023^{*}$ \\
\hline No & 27 & 12 & 15 & & & 14 & 13 & & \\
\hline
\end{tabular}

GLUT-1, glucose transporter 1; HIF-1a, hypoxia inducible factor $1 a$; HNSCC, head and neck squamous cell carcinoma

* denotes statistical differences $(P<0.05)$. 


\begin{tabular}{|c|c|c|c|c|c|c|c|c|c|}
\hline \multirow[t]{2}{*}{ Factors } & \multirow[t]{2}{*}{ Case } & \multicolumn{2}{|c|}{ GLUT-1 } & \multirow{2}{*}{$\chi^{2}$} & \multirow[t]{2}{*}{ P value } & \multicolumn{2}{|c|}{ HIF-1a } & \multirow{2}{*}{$\chi^{2}$} & \multirow[t]{2}{*}{$P$ value } \\
\hline & & + & - & & & + & - & & \\
\hline \multicolumn{10}{|c|}{ Metastasis } \\
\hline Yes & 11 & 11 & 0 & 11.121 & $0.001^{\star}$ & 11 & 0 & 7.710 & $0.005^{\star}$ \\
\hline No & 35 & 15 & 20 & & & 19 & 16 & & \\
\hline \multicolumn{10}{|c|}{ Second primary cancer } \\
\hline Yes & 5 & 4 & 1 & 1.258 & 0.262 & 5 & 0 & 2.992 & 0.084 \\
\hline No & 41 & 22 & 19 & & & 25 & 16 & & \\
\hline \multicolumn{10}{|c|}{$\begin{array}{l}\text { GLUT-1, glucose transporter } 1 \text {; HIF-1a, hypoxia inducible factor } 1 a \text {; HNSCC, head and neck squamous } \\
\text { cell carcinoma }\end{array}$} \\
\hline
\end{tabular}

Figures 


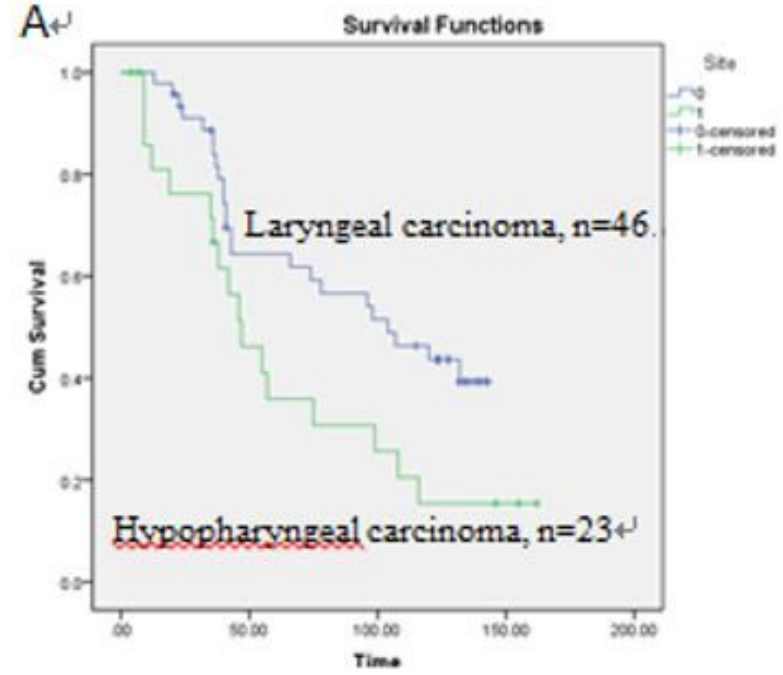

(A) Survival analysis in patients with laryngeal carcinoma and hypopharyngeal carcinoma $(P=0.024)$

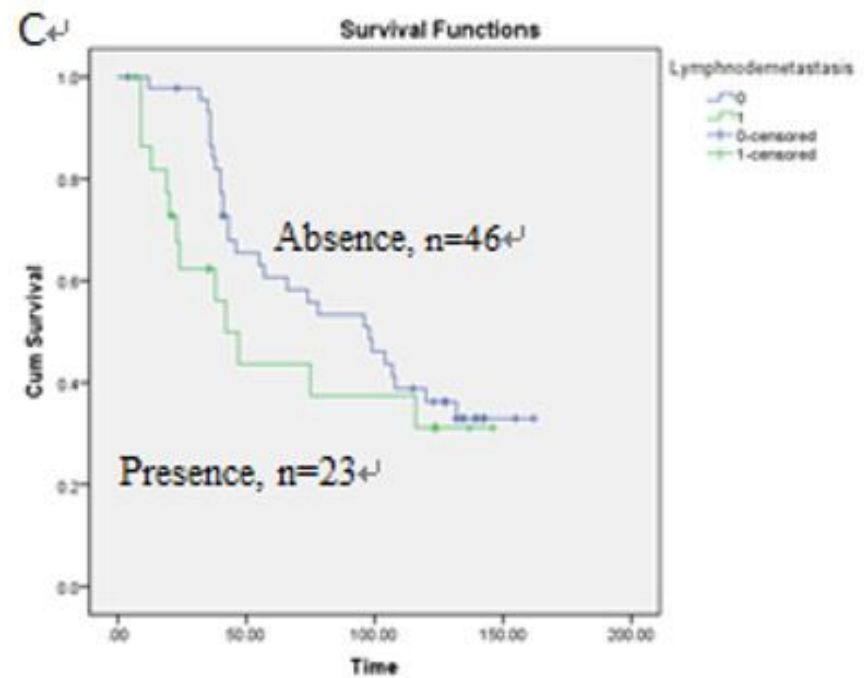

(C) Survival analysis according to the presence or absence of lymph node metastasis $(P=0.039)$

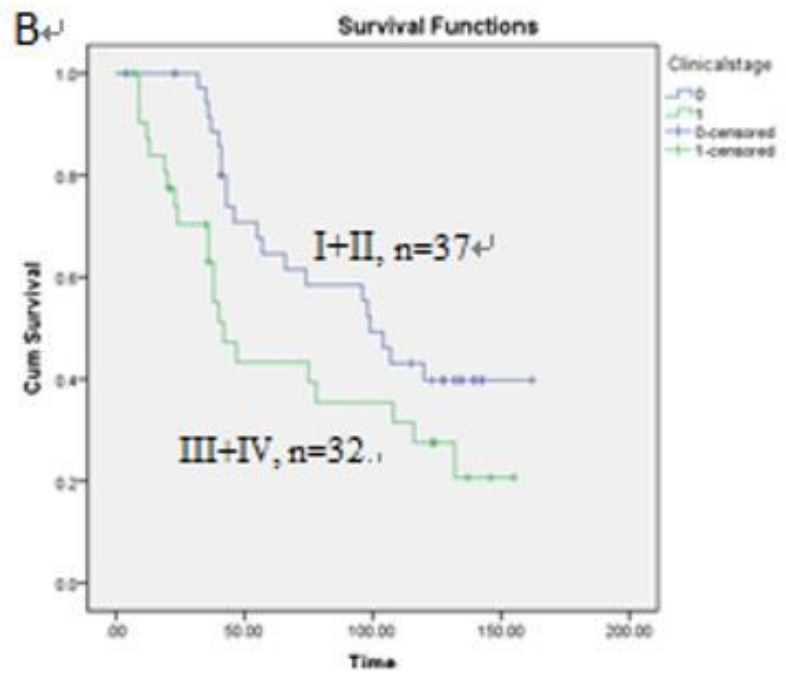

(B) Survival analysis according to clinical stage $(P=0.041)$

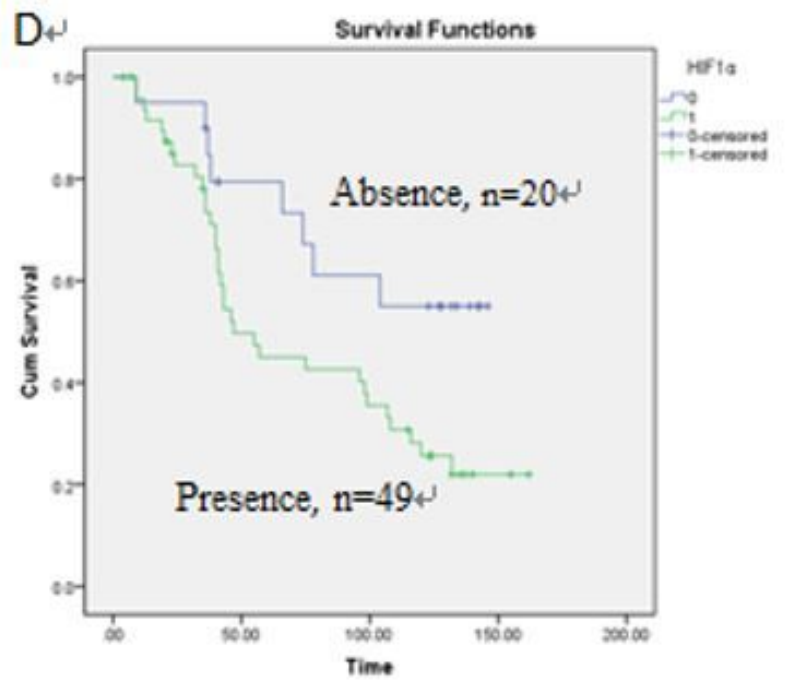

(D) Survival analysis according to the presence or absence of HIF-1a expression $(P=0.029)$

\section{Figure 1}

Survival analysis in patients with HNSCC. HNSCC, head and neck squamous cell carcinoma; HIF-1a, hypoxia-inducible factor- $1 \mathrm{a}$. 


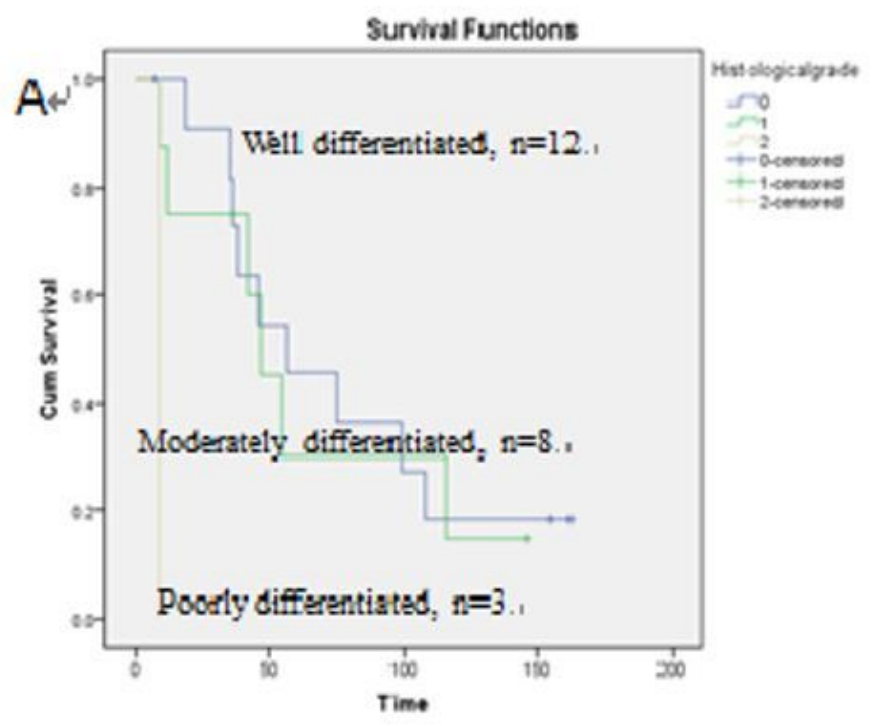

(A) Survival analysis in hypopharyngeal carcinoma patients according to histological grade $(P=0.002)$

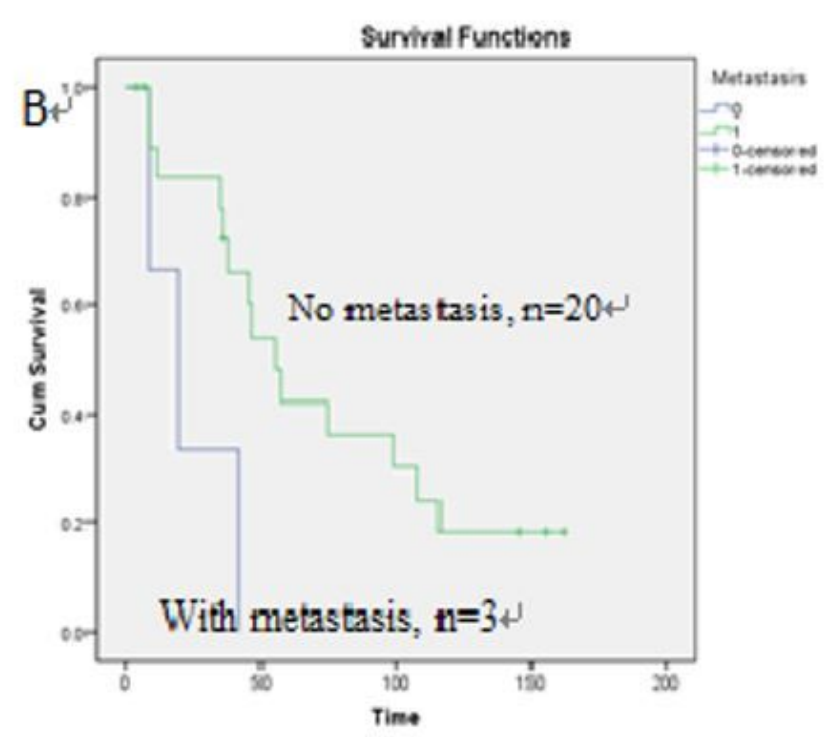

(B) Survival analysis according to the presence or absence of metastasis $(\mathrm{P}=0.022)$

\section{Figure 2}

Survival analysis in patients with hypopharyngeal carcinoma. 


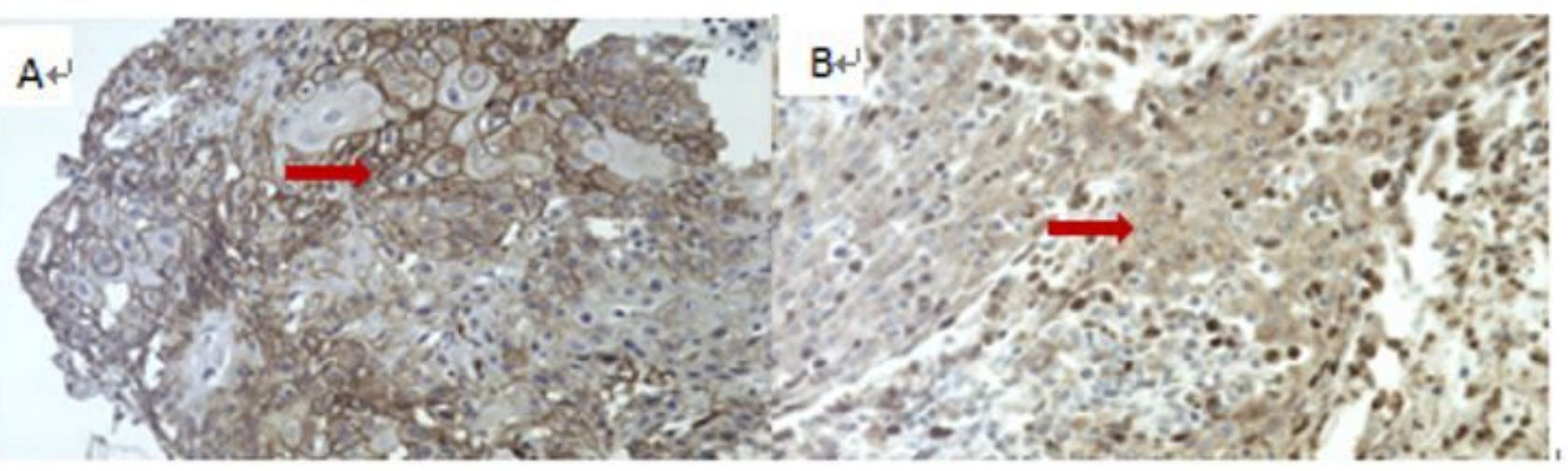

(A) GLUT-1 showed positive and diffuse expression in laryngeal carcinoma (arrow) (magnification, $\times 400$ )..

(B) HIF-1 $\alpha$ showed positive and diffuse expression in laryngeal carcinoma (arrow) (magnification, $\times 400$ ).

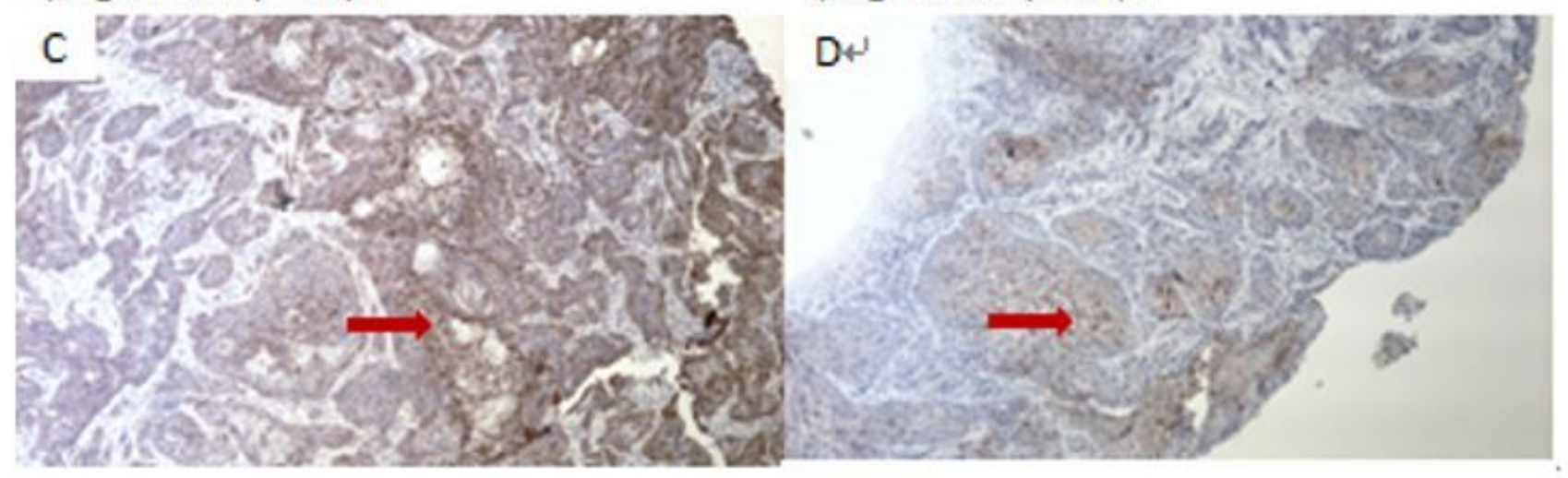

(C) GLUT-1 showed positive and diffuse expression in hopopharyngeal carcinoma (arrow) (magnification, $\times 400$ ).

(D) HIF-1 $\alpha$ showed positive and diffuse expression in tropopharyngeal carcinoma (arrow) (magnification. $\times 100$ ).

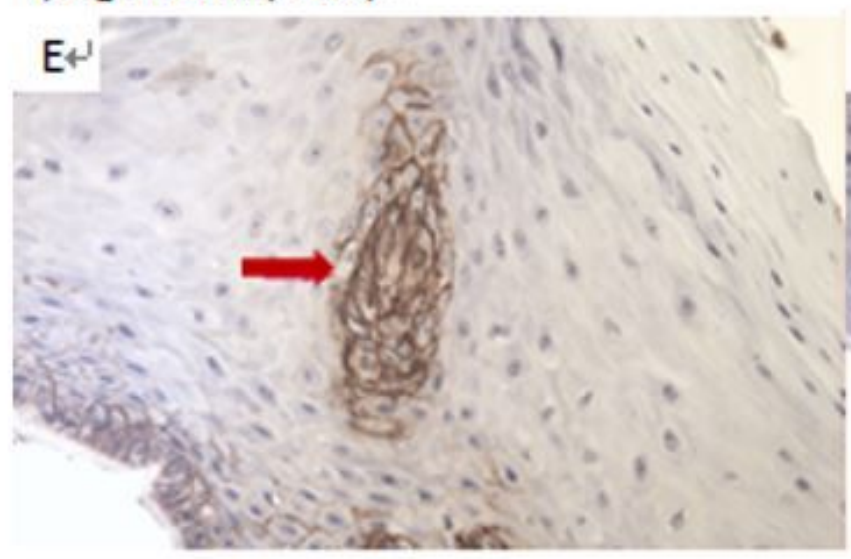

(E) GLUT-1 was locally positive in vocal cord levkoplakia (arrow) (magnification, $\times 400$ )..

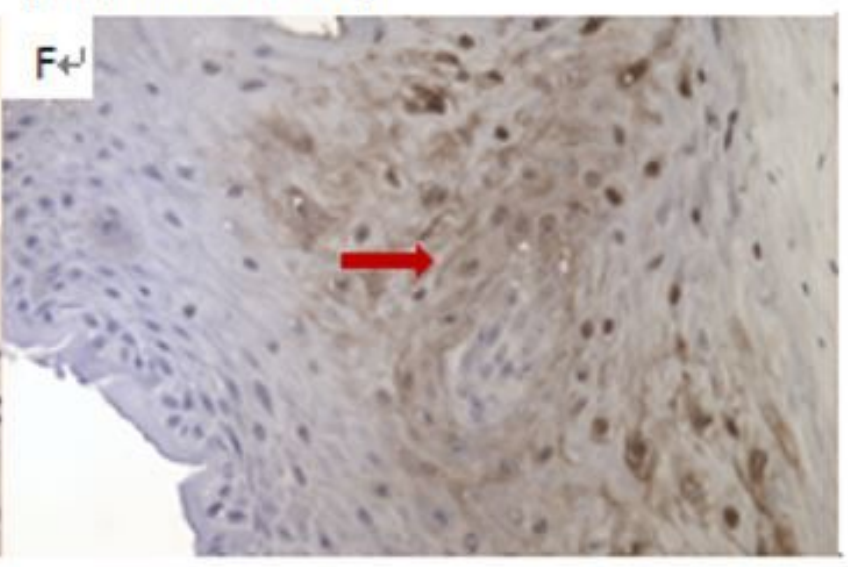

(F) HIF-1 $\alpha$ was weakly positive in vocal cord leukoplakia (arrow) (magnification, $\times 400$ ). .

\section{Figure 3}

On immunostaining analysis, GLUT-1 and HIF-1 a protein expression were positive in laryngeal carcinoma and hypopharyngeal carcinoma, locally or weakly positive in vocal cord leukoplakia, and negative in vocal cord polyps. 